\title{
The complexity of roles of P-glycoprotein in refractory epilepsy: pharmacoresistance, epileptogenesis, SUDEP and relapsing marker after surgical treatment
}

\author{
Alberto Lazarowski ${ }^{1,2, \mathrm{f} *}$, Liliana Czornyj ${ }^{2,3, \mathrm{f}}$, Luisa Rocha ${ }^{4, \mathrm{f}}$ \\ ${ }^{1}$ INFIBIOC, FFyB-University of Buenos Aires (UBA), Junin 956 (1113), CABA, Argentina \\ ${ }^{2}$ Fundacion Investigar, Riobamba 426 P-15 (1025), CABA, Argentina \\ ${ }^{3}$ Servicio de Neurologia, Hospital Juan P. Garraham, Combate de Los Pozos 1881 (1245), CABA, Argentina. \\ ${ }^{4}$ Pharmacobiology Department, Center for Research and Advanced Studies, DF, Mexico. \\ ${ }^{f}$ Members of GENIAR (Cyted 610RT0405) \\ *Corresponding Author: E-mail: alazarowski@gmail.com; Tel +54-11-4304-2611
}

Received: January 29, 2015; Revised: May 04, 2015; Published: July 01, 2015

\begin{abstract}
As described initially from clinical and experimental studies, $P$-glycoprotein ( $P$-gp) plays a central role in the pharmacoresistance of epilepsy, acting by efflux of AEDs mainly at blood brain barrier (BBB) level. However, repetitive seizures can produce both brain and heart P-gp overexpression. Because P-gp activity induces membrane depolarization, its neuronal expression could be acting in the intrinsic mechanism of epileptogenesis, and its heart expression, can be a high risk factor of death, after severe-continuo convulsive stresses as in fatal status epilepticus or in SUDEP. Additionally, because P-gp is also a stem cell marker, we suggests that its constitutive overexpression in dysplastic neurons from brain epileptogenic areas observed in patients with refractory epilepsies, should be addressed as a risk factor of seizures relapse after surgical treatment. Here we discuss these concepts, based on our own clinical and experimental experiences, and reviewing the current literature on these subjects.
\end{abstract}

\section{Keywords}

P-glycoprotein; membrane depolarization; drug resistance; SUDEP, biomarker, long-term relapse

\section{"What is a seizure and what is epilepsy?"}

Seizures and epilepsy are not the same. It is defined that seizure as "the abnormal excessive or synchronous neuronal activity in the brain" that can be produced secondary to a wide spectrum of injuries. However, "epileptic seizures" are produced spontaneously, so, a seizure is an event and epilepsy is a disorder involving recurrent unprovoked seizures. After several years of deliberations on this issue have now been published the result from International League Against Epilepsy (ILAE) commissioned second task force, to develop a practical (operational) definition of epilepsy, designed for use by doctors and patients [1], and adopted as a position of the ILAE. Some comments were published to better understanding of this definition, however, it is limited to a observational clinical level [2,3], and not 
describe the cellular or sub-cellular mechanistic process that involve alterations on functional properties of the neuronal membrane.

Epilepsy is the second most common neurological disorder after cerebrovascular accident (CVA) or stroke, and it is estimated that approximately $\sim 1.0-2.0 \%$ of the population is affected by different forms of epilepsy. Interestingly, near $30 \%$ of epilepsies, have identifiable injuries to the brain that triggered the development of the named symptomatic epilepsies [4]. So, a non-specific damaging factor producing a brain injury can develop symptomatic epilepsy after a very complex subclinical process, which links this mentioned first insult with the clinically expressed first spontaneous epileptic seizure. And this particular and multifactorial process is recognized as latency phase or "epileptogenesis".

This cellular/molecular phenomenon is started after the brain injury and can be facilitated by some conditions as age, co-morbidity, medications, etc. Blood brain barrier (BBB) damage, angiogenesis, gliosis, inflammation, axonal sprouting or injury, acquired channelopathies, and changes of dendritic plasticity, are some of long list of modifications observed during this latency phase. Because a wide spectrum of different forms of brain injuries can lead in a secondary epileptic syndrome, it is important to add that the presence of background genes, developmentally regulated genes and/or epigenetic factors, can play a role in these process. Perhaps, stroke, brain hypoxia and/or status epilepticus are the more clear conditions that can develop secondary epilepsy as well as to disclose a refractory phenotype [5].

Neuronal excitability can arise from structural/functional changes at the postsynaptic membrane level, alterations in the type, number, and distribution of voltage- and ligand-gated ion channels or biochemical modification of receptors that increase permeability to $\mathrm{Ca}^{2+}$, favoring development of the prolonged depolarization that precedes seizures. Excessive excitation is the key factor underlying ictogenesis, which may originate from individual neurons, the neuronal environment, or neuronal networks [6]. The imbalance between the excitatory (high) and the inhibitory (reduced) stimuli are the main mechanism of neuronal membrane depolarization and the onset of seizures.

Neuronal axons have a resting membrane potential of about $-70 \mathrm{mV}$ inside vs outside. Action potentials occur due to net positive inward ion fluxes, resulting in local changes in the membrane potential. Membrane potentials vary with the activation of either ligand- or voltage-gated ion channels, which are affected by changes in either the membrane potential or intracellular ion concentration. When a neuron is at $-70 \mathrm{mV}$ it is said to be at resting potential. Here, a neuron is not being excited by anything and is basically asleep, awaiting input from other neurons. Resting potential is maintained by the sodiumpotassium pump, which constantly pushes sodium out of the neuron. The pump operates via a bunch of sodium-potassium transporters located along the membrane. These transporters push three sodium molecules out for every two potassium molecules it takes in. Resting potential exists when sodium is on the outside of the cell and potassium is on the inside.

When a neuron is excited the membrane potential shoots from $-70 \mathrm{mV}$ to about $40 \mathrm{mV}$ and the membrane is depolarized. The excitability of synaptic terminals depends on the amount of excitatory neurotransmitter released (e.g., glutamic acid or activation of glutamergic receptors) as well as of an insufficient amount of inhibitor neurotransmitter released (e.g., $v$-aminobutyric acid, or GABA), and consequently of the final extent of membrane depolarization produced. Interestingly, through the axis glutamate/NMDA receptor/cyclooxygenase-2 (COX-2) signaling, glutamate can induces overexpression of P-glycoprotein (P-gp) in brain $[7,8]$. The efflux of drugs by the multidrug transporters, particularly P-gp 
(ABCB1-transporter) is one of the principal means by which several patients with pharmacoresistant epilepsy develops refractoriness to a wide spectrum of antiepileptic drugs (AEDs) $[9,10]$.

The questions are how so different factors and cellular/molecular process underlying during brain injury, can induce an enduring phenomenon with chronically recurrent seizures and why persistent (without control) convulsive stress is a main risk factor of develop pharmacoresistant epilepsy? So, is the acquired refractoriness an inducible process?

\section{ABC-transporters: P-glycoprotein}

The movement of different compounds as solutes, nutrients, ions, toxics or drugs across cell membranes is a critical biological process where the ATP-binding cassette (ABC) transporter's family plays a central role and represents one of the largest families of transport proteins [11-13]. Several functional properties of these transporters have been described and their importance is indicated not only by the large number of encoding genes, or their ubiquitous expression, but also by their ancestral origin and because 22 of 48 human $A B C$ proteins are implicated in human diseases [14]. The presence of these pumps in the liver, bowel, and kidney and BBB suggests that these transport systems have evolved to protect the organism against, endogenous/circulating chemicals, xenobiotics, organic ions, and drugs [15].

Particularly the P-gp was the first eukaryotic ABC-transporter identified conferring multidrug resistance to cancer cells $[16,17]$. P-gp has a molecular architecture with a core structure of two pairs of domains of nucleotide binding domain (NBD) where ATP is hydrolyzed and the transmembrane domain (TMD) that consists of six transmembrane helices and where is the drug- binding site.

The mechanistic way of drugs transport is based on conformational changes at the NBDs level, transmitted to the TMDs, and producing the drug export that is energy ATP-dependent $[18,19]$. An "alternating catalysis model" have been described indicating that after ATP hydrolysis, ADP could be trapped at one of two NBDs.

Normally, in the absence of nucleotide (state I), the two opposing domains of the ATP sites are in the "open" conformation, and the binding of two molecules of ATP results in the formation of the nucleotide sandwich (state II) that draws together the opposing faces of the ATP sites. This is followed by a conformational change in which one of the two ATPs is "occluded" in a non-exchangeable form (state III) (Figure 1)[20].

\section{ABC-transporters in the brain}

The central nervous system (CNS) effects of many therapeutic drugs are blunted because of restricted entry into the brain. The basis for this poor permeability is the brain capillary endothelium, which comprises the BBB. This tissue exhibits very low paracellular (tight junction, or TJ) permeability and expresses a potent system of drug export pumps. The BBB is a highly specialized structural and biochemical barrier that regulates the entry of blood-borne molecules and cells into the brain and preserves ionic homeostasis within the brain microenvironment. 


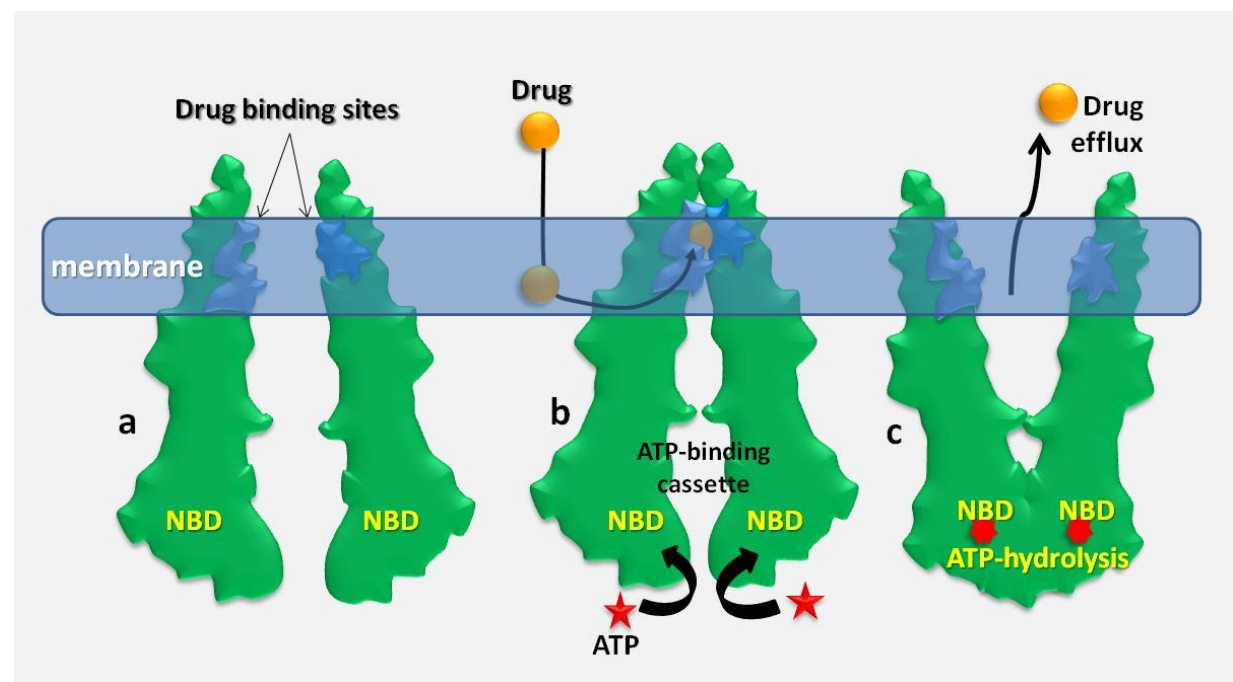

Figure 1: Drug efflux cycle: the drug binds first to the TMD producing conformational changes of ABC-transporter. a) State I: The inactive structure of P-gp. b) State II: The inward-facing conformation. c) State III: The outward-facing conformation

Transporters are abundantly expressed in the brain, mainly in the vascular endothelial cells (VEC) of the BBB, the epithelial cells of the brain-cerebrospinal fluid barrier (BCSFB), and also some parenchyma cells in brain, particularly in the food-ending process of astrocytes-touching VEC of vessels. Drug uptake into the brain highly depends on the efflux transporters expressed at both BBB and BCSFB biological barrier systems.

A polarized location of the drug efflux transporters is mainly present on the luminal (apical or blood) side of the endothelial cells in the brain capillary where P-gp, BCRP, and MRP2 are unequivocally expressed at the blood side. This natural distribution of the main drug-transporters at $\mathrm{BBB}$, indicates that the normal presence of some ABC-transporters (including P-gp) at BBB level, is not enough to produce the impairment of AEDs entrance in the brain for the responders patients. The "transporter's hypothesis" to explain the refractoriness in epilepsy need not only a functional up-regulation of these transporters at BBB level to clean/export AEDs, but also they should be expressed on previously non-expressing cell as neurons. The inducible properties of these transporters as well as the the pharmacoresistant phenotype [9] links pharmacoresistance with epileptogenesis, as discussed below.

\section{P-glycoprotein and drug resistant phenotype in epilepsy}

One-half of newly diagnosed patients with epilepsy obtain full seizure control with the first AED trial, and $13 \%$ more enter remission with the addition of a second drug. However, the $30-40 \%$ of the remaining patients are not to obtain satisfactory seizure control in spite of different drug combinations.

It is clear the wrong choice of AEDs may be the cause of treatment failure. However, with the correct therapeutic stratagem, Sanjay M. Sisodiya (2006) suggests that patients, who were considered drug resistant, may not remain so as newer AEDs are developed or designed to new target previously unappreciated underlying pathophysiological mechanisms. Additionally, he suggests that for individuals who we could define as being drug resistant, perhaps their epilepsy is considered "drug resistant" simply because we do not yet have the appropriate drugs for the treatment [21]. However, in spite of the increased amount of new AEDs developed during the last 30 years, the same percentage (30-40\%) of pharmacoresistant patients remains without modifications (Fig. 2). 


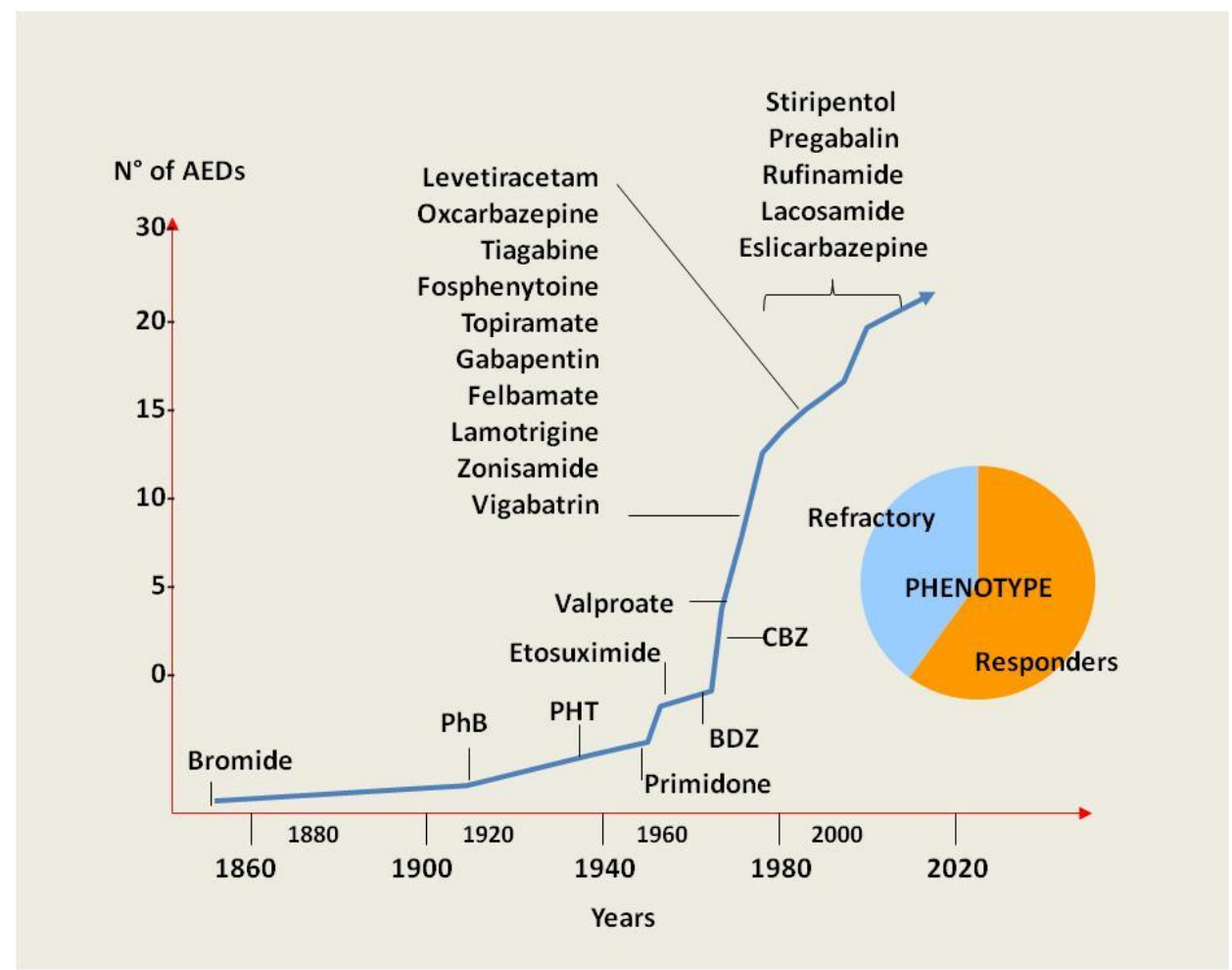

Figure 2: The increase of new AEDs not decrease the percentage of drug-resistant cases (Modified from Czornyj \& Lazarowski: Genetics of Epilepsy and Refractory Epilepsy. Ed. Michael Dean. COLLOQUIUM SERIES ON THE GENETIC BASIS OF HUMAN DISEASE, Morgan \& Claypool Life Sciences, 2013)

After the initial descriptions of the potential association between P-gp overexpression in the brain and refractory epilepsy [22,23], several other groups have reported high levels of P-gp expression in epileptogenic brain specimens from patients with refractory epilepsy. In these studies, P-gp was highly expressed not only in endothelial cells of BBB but also in brain parenchymal cells $[9,10,24-26]$.

Similar results were observed by independent experimental studies of different epileptic models, such as a single dose of intra-cerebroventricular kainic acid, chronic epilepsy, repetitive PTZ-induced seizures and pilocarpine-induced status epilepticus. In these studies, seizure-induced overexpression of P-gp at BBB and brain parenchyma cells as astrocytes and neurons were described [25,27-29]. Furthermore, after repetitive induced seizures, the simultaneous high P-gp expressions in different brain regions and liver or heart have been reported [30,31].

\section{P-glycoprotein and pharmacokinetics alterations}

Refractory epilepsy is described in patients receiving recommended AEDs doses, have an adequate therapeutic levels of AEDs in plasma, but remains without control of seizures. It was demonstrated that therapeutic levels of phenytoin (PHT) in blood and CSF can be achieved independently of the route of administration, as long as conventional loading doses are used, and in the case of PHT i.v. administration, 2 $h$ are enough to reach steady state concentrations within the therapeutic range [32]. As previously described in two cases reports [23,33], patients can have persistent low plasmatic levels of at least one of the AEDs administered, despite their scrupulous compliance with the prescribed drugs regimen. Often, laboratory professionals and physicians have no rational explanations, and non-detectable errors in AED measurement procedures and methods are assumed. Most AEDs are substrates of P-gp, and the inducible nature of this $A B C$-transporter gene suggests that over-expression of this protein can be observed in all 
excretory organs including BBB, playing a critical role in the modification of both systemic and local pharmacokinetics of AEDs.

Experimentally, it was also demonstrated that brain P-gp overexpression, correlated with the lower hippocampal phenytoin concentration in a refractory epileptic model, and whereas the administration of an antagonist of P-gp such as nimodipine $(2 \mathrm{mg} / \mathrm{kg}$ ) restored the normal central PHT pharmacokinetics [34].

Clinically and experimentally, the uses of some calcium channel blockers have been described to increase plasmatic levels of AEDs simultaneously with the recovery of seizures control $[35,36]$.

It is known that ABC-transporters are located at the apical membrane of both acinar and ductal cells [37]. Those proteins are important determinants of interindividual differences in intestinal absorption or hepatic clearance, and hence plasma levels of some if not all AEDs. These variations can also be detected by measurement of saliva drug concentration, and it is sensitive enough for detecting systemic clearance changes. Furthermore, some AEDs would modify their bioavailability and clearance by inducing efflux transporter throughout chronic treatments, from the first dose to multiple dose administration and it can be documented by saliva drug concentrations. It is important to notice the usefulness of salivary drug concentrations to determine systemic clearance in patients not only from a pharmacokinetic point of view but also as new index to phenotype epileptic patients as refractory to the pharmacological treatment [38].

lannetti et al. [39] recently described 11-years-old boy who developed status epilepticus, after a prolonged right-side simple partial motor seizure, which was unresponsive to long term aggressive treatment with several AEDs. Control of convulsive seizures was achieved at valproic acid plasma level of $108 \mu \mathrm{g} / \mathrm{ml}$, but electrical status epilepticus persisted, and the child remained comatose. On day 37, a treatment with verapamil (blocker of calcium L-channel and P-gp) was started and 1.5 hour after the initiation the infusion, the patient regained consciousness, was able to breathe spontaneously, and the status epilepticus, promptly disappeared. The authors suggested that verapamil, a known P-gp inhibitor acted by facilitating the brain penetration of AEDs simultaneously administrated to the patient.

\section{Role of P-glycoprotein in epileptogenesis}

Taking in account that in a normal brain, neurons do not express P-gp, which could be the functional changes in neurons expressing P-gp,?

Approximately one third of patients with epilepsy do not have satisfactory control of seizures with antiepileptic drugs (AEDs) and it is suggested that drug resistant phenotype could be present at the early stage of the disease [40].

At present, antiepileptic drug refractoriness has been explained by the "reduced drug-target sensitivity" and the "drug transporter overexpression" hypotheses.

MDR-1 gene upregulation could be acquired as a consequence of repetitive non-controlled seizures $[28,29]$ as well as secondary to pathological conditions such as inflammation, tumors or hypoxia [41-44], supporting the idea that silent mechanisms could overexpress P-gp in brain before epilepsy and refractoriness becomes clinically evident. Repetitive seizures, status epilepticus as well as brain hypoxia induces P-gp expression in neurons. This P-gp induced expression depends on the frequency and intensity of seizures and is related to a progressive increase of the pharmacoresistant phenotype [45]. Furthermore, the induced "de novo" expression of P-gp in previously non-expressive cells as observed particularly in 
neurons from epileptogenic brain areas, suggests a differential role of this transporter, perhaps related to the intrinsic convulsive mechanism $[29,33,46]$.

In this regard, a group of evidence indicates that P-gp can also decrease the plasma membrane potential of several cell types $[47,48]$ and modify swelling-activated $\mathrm{Cl}^{-}$currents [49], both physiologic disturbances observed during brain hypoxia [50] and convulsive stress [51]. According to these observation, recently was reported the first study demonstrating that daily PTZ-induced seizures produces simultaneously the progressive acquisition of pharmacoresistant phenotype, increased brain P-gp expression and high membrane depolarization in brain areas such as hippocampus and cortex [52]. In this study, the recovery of potential membrane of depolarized slides in hippocampus and neocotex (in vitro experiments) was induced when PHT was combined with nimodipine, a calcium channel blocker that also inhibit P-gp function.

In addition to the much known drug pump model, some studies indicate that P-gp may mediate drug resistance through channels function regulation [53]. Supporting this idea, it has been described that MDR1 protein behaves as some type of $\mathrm{Cl}^{-}$transporter, stimulates $\mathrm{Cl}^{-}$channel activity and may alter cell volume in several cell types [54]. Its overexpression leads to decreased plasma membrane electrical potential by increasing $\mathrm{Cl}^{-}$permeability and thus decreasing the dominance of membrane potential by $\mathrm{K}^{+}$conductance, and leads to altered pHi regulation $[47,48]$. So, brain P-gp overexpression could contribute to crucial factors detected in several types of epilepsy such as the intracellular acidosis associated with altered $\mathrm{Na}^{+} / \mathrm{H}^{+}$exchange [55], enhanced extracellular concentration of potassium [56], and particularly in the increased membrane depolarization [57].

Considering all the mentioned evidences, the popular comments saying that "seizures induce seizures" and "seizures without control induce refractoriness" could have a mechanistic and molecular explanation, where progressive and induced P-gp expression in neurons reduces the membrane potential and the seizure thresholds, and increasing the risk of pharmacoressitance. Consequently, how much time P-gp can be expressed in brain cells after an initial inducer insult?

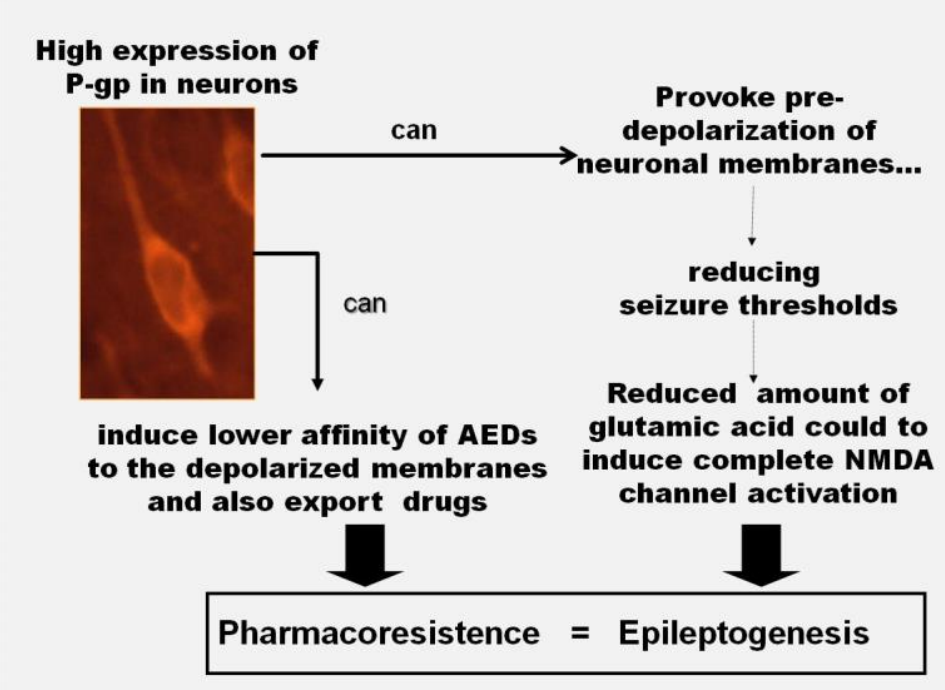

Figure 3: Neuronal expression of P-gp (white arrow) can be induced by seizures, hypoxia, inflammation, drugs, cytokines, tumors, metabolic disorders, toxics, trauma, or infections. Irrespective which was the cause, in these conditions neuronal membranes will be depolarized. Interestingly, all these mentioned factors are the more common conditions that develop acquired epilepsy. 
The time course for the expression of P-gp in astrocytes after status epilepticus following intracerebroventricular kainate injection, was 10 consecutive weeks [25], and after the cortical devascularization inducing focal hypoxia, P-gp expression in neurons was maximal at day 7 , and remained lightly positive at day 28 [58]. P-gp could be expressed longer times depending on the severity and also the frequency of the repetitive inducer stimulus. So, we can speculate that time during neuronal P-gp remains expressed, results in a pharmacoresistant window, or the time during the patients have higher risk to get a new seizures, or both conditions. If it is the case, pharmacoresistance and epileptogenesis are sharing the same mechanistic risk factor: "P-gp expressed in neurons".

\section{P-glycoprotein and Sudden Unexpected Death in Epilepsy (SUDEP)}

Patients with Refractory Epilepsy carry an increased mortality risk of that is more elevated than in patients with well-controlled seizures. The sudden, unexpected, witnessed or unwitnessed, no traumatic and no drowning deaths in patients with epilepsy, is usually a clinical phenomenon in which post-mortem examination does not reveal a toxicological or anatomical cause of death [59]. The clinical characteristics of patients with epilepsy at particular risk for SUDEP are related with a long history (more than 15 years) of pharmacoresistant epilepsy or high seizure frequency (more than 15 seizures/moth). All these patients currently receive antiepileptic drug (AED) polypharmacy, and commonly changes between different therapeutic combinations and/or doses. Persistent low levels of AEDs in plasma as well as poor adherence to pharmacotherapy are also observed in these patients, and several of all of these features are associated to pharmacoresistant epilepsy [60].

Different studies have suggested that seizure activity as inducer of cardiovascular alterations, changes in the respiratory rate including tachypnea, hypopnea or apnea, related also with heart ischemia, suggesting that respiratory and mainly cardiovascular abnormalities during and between seizures, could play a central role in SUDEP [61-63]. It was also experimentally demonstrated that after both acute or chronic heart hypoxia, P-glycoprotein results to be overexpressed in cardiomyocytes and associated with heart stunning $[64,65]$.

According with these observations it is important notice that continuous convulsive stress could mimic a repetitive apneas or hypoxia and produce heart ischemia. In bases to these considerations, the progressive and simultaneous P-gp overexpression in brain and heart, related with the development of fatal status epilepticus after experimental repetitive seizures was recently demonstrated by our group [66]. Furthermore, we can speculate that high P-gp expression in brain, particularly in neurons (as previously described above), could play a role on the risk for SE development, and high P-gp expression in heart could play a role in the risk for develop an acute and fatal heart failure.

\section{P-gp as stem cell marker of brain malformation/tumor refractory epilepsies and/or relapsing marker after surgical treatment}

Several malformations of cortical development as well as brain tumors are associated with refractory epileptic syndromes and/or developmental delay. The main developmental brain abnormalities identified are hemimegalencephaly, polymicrogyria, agyria-pachygyria, schizencephaly, heterotopic gray matter, transmantle dysplasia, focal cortical dysplasia, or cortical tubers. P-gp and others ABC-transporters have been reported to be over-expressed in these malformations of cortical development and brain cortical tubers explaining why all of them are clinically characterized by phamacoresistant phenotype $[22,23,67,68]$. Epilepsy is also common disorder in patients with brain tumors and can substantially affect 
daily life, even if the tumor is under control. In these cases, multidrug-ABC-transporters expressed at blood brain barrier, brain tumor cells and tumor-surrounding cells, prevent the access of antiepileptic drugs into brain parenchyma, and patients develop a refractory phenotype.

In Subependimmal Giant Astrocytoma (SEGA), ABC-transporters (P-gp and BCRP) and CD34 stem cell markers were highly expressed in non-vascularized tumor cells. Heterogeneous distributions for these markers were detected with differential immunostaining pattern, showing high immunoreactivity in SEGA cells far of vessels, and low or negative expression in SEGA cells near the vessels. This particular expression pattern of both ABC-transporters, and CD34 antigen could identify different stem-cell subset in SEGA [69].

Similarly, co-expression of CD34 and neurofilament were described in epilepsy-associated glioneuronal tumors [62,70]. In normal brain, CD34 occurs only transiently during neurulation [71] and recently CD34 immunoreactivity was also detected as a subpopulation of balloon cells confined to the white matter but not observed in neocortical layers from brain specimens of Taylor's focal cortical dysplasia [72].

Tissues from therapeutic resections of several refractory epilepsies, as dysembryoplastic neuroepithelial tumors, focal cortical dysplasia and hippocampal sclerosis, as well as several brain tumors as glial and glioneuronal tumors, are associated with pharmacoresistant epilepsy, having a much poorer pharmacological outcome compared to other symptomatic epilepsies. In all of them, overexpression of ABC-transporters as P-glycoprotein, MRPs and BCRP were described [10,24,45,69,73].

ABC-transporters, particularly P-gp and BCRP, are transiently expressed at high levels in human neural stem/progenitor cells (hNSPCs) but are downregulated in differentiated hNSPCs, and in normal conditions, they are expressed in a highly regulated manner, with the highest expression in primitive cells and subsequent down-regulation following commitment to differentiation [74]. Furthermore, the constitutive deficiency of $A B C$-transporters leads to distinct impairments in neural stem/progenitor cells maturation and adult neurogenesis in vivo, indicating a functional role of $A B C$-transporters in stem cell maintenance and differentiation [75]. All these data clearly suggests that presence of ABC-transporters, in abnormal and immature brain cells as well as in immortalized tumor cells, are clearly a hallmark of a non-fully differentiated progenitor cell. If it is the case, ABC-transporters together other stem cell markers, could build a new biomarkers profile to give predictive information for long-term follow-up of surgically treated refractory epilepsies and/or related with the risk of relapse of seizures, even before that a new brain structural anomaly can be detected. Furthermore, at date, the available evidence demonstrates that longterm seizure freedom is achieved in about $60 \%$ of patients who undergo temporal lobe surgery, and in $30-$ $40 \%$ of those who undergo extratemporal surgery [76].

\section{Conclusions}

It is important to distinguish between the truly drug-transporter properties of these proteins leading to the pharmacoresistant phenotype, from those related with plasmatic membrane depolarization inducing pro-epileptic effects, directly related with epileptogenesis as described for P-gp. In this sense, ABCtransporters, as P-glycoprotein and BCRP, could be interpreted as stem-cell markers presents in several brain cortical malformations, being constitutive components of immature not-fully differentiated cells, as observed in dysplastic neurons and ballooned cells or brain tumor cells. Interestingly, all these abnormal cells that also play a role in the epileptogenesis, have high expression of ABC-transporters and are also refractory to AEDs. Under these conditions, repetitive seizures can induce simultaneous P-gp overexpression in both brain and heart. It could be a combined risk factor to develop an acute heart failure under severe stress triggered by status epilepticus resulting in a fatal end. 
Finally, the condition of $A B C$-transporters as stem cell markers, if they are presents in those mentioned abnormal cells, could contribute to build a risk score or predictive profile for long-time seizures relapse after surgical treatment.

\section{References}

[1] R.S. Fisher, C. Acevedo, A. Arzimanoglou, A. Bogacz, J.H. Cross, C.E. Elger, J. Jr. Engel, L. Forsgren, J.A. French, M. Glynn, D.C. Hesdorffer, B.I. Lee, G.W. Mathern, S.L. Moshé, E. Perucca, I.E. Scheffer, T. Tomson, M. Watanabe, S. Wiebe, Epilepsia 55 (2014) 475-482.

[2] R.S. Fisher, Epilepsia 55 (2014) 492-493.

[3] E. Perucca, Epilepsia 55 (2014) 473-474.

[4] W.A. Hauser, Incidence and prevalence. In: J. Engel Jr, T.A. Pedley, editors. Epilepsy: a comprehensive textbook. Philadelphia: Lippincott-Raven;1997. p.47-57

[5] A. Pitkänen and K. Lukasiuk, Epilepsy \& Behavior 14 (2009) 16-25.

[6] S. Engelborghs, R. D’Hooge, P.P. De Deyn, Acta Neurol. Belg. 100 (2000) 201-13.

[7] B. Bauer, A.M. Hartz, A. Pekcec, K. Toellner, D.S. Miller, H. Potschka, Mol. Pharmacol. 73 (2008) 1444-53.

[8] R.W. Robey, A. Lazarowski, S.E. Bates, Mol. Pharmacol. 73 (2008) 1343-6.

[9] A. Lazarowski, L. Czornyj, F. Lubienieki, E. Girardi, S. Vazquez, C. D’Giano, Epilepsia 48 (2007) s5,140-149.

[10] S.M. Sisodiya, W.R. Lin, B.N. Harding, M.V. Squier, M. Thom, Brain 125 (2002) 22-31.

[11] M. Dean, Y. Hamon, G. Chimini, J. Lipid Res. 42 (2001) 1007-17.

[12] M. Dean, T. Annilo, Annu. Rev. Genomics Hum. Genet. 6 (2005) 123-42.

[13] M.M. Gottesman, S.V. Ambudkar, J. Bioenerg. Biomembr. 33 (2001) 453-8.

[14] V. Ling, J. Nat. Cancer Inst. 81 (1989) 84-85.

[15] C. Cordon-Cardo, J.P. O'Brien, J. Boccia, D. Casals, J.R. Bertino, M.R.Melamed, J. Histochem. Cytochem. 138 (1990) 1277-1287.

[16] M.M. Gottesman, T. Fojo, S.E. Bates, Nat. Rev. Cancer 2 (2002) 48-58.

[17] C.F. Higgins, I.D. Hiles, G.P.C. Salmond, D.R. Gill, J.A. Downie, I.J. Evans, I.B. Holland, L. Gray, S.D. Buckel, A.W. Bell, M.A. Hermodson, Nature 323 (1986) 448-50.

[18] A.L. Davidson, J. Bacteriol. 184 (2002) 1225-33.

[19] C.F. Higgins, K.J. Linton, Nat. Struct. Mol. Biol. 11 (2004) 918-26.

[20] Z.E. Sauna, S.V. Ambudkar, Mol. Cancer Ther. 6 (2007) 13-23.

[21] S.M. Sisodiya, Epilepsia 46 (2005) (Suppl 10) 33-8.

[22] D. Tishler, K. Weinberg, D. Hinton, N. Barbaro, A. Geralyn, R. Corey, Epilepsia 36 (1995) 1-6.

[23] A. Lazarowski, G. Sevlever, A. Taratuto, M. Massaro, A. Rabinowicz, Ped. Neurol. 21 (1999) 731-734.

[24] A.J. Lazarowski, F.J. Lubieniecki, S.A. Camarero, H.H. Pomata, M.A. Bartuluchi, G. Sevlever, A.L. Taratuto. Pediatr. Neurol. 34 (2006) 20-4.

[25] L. Zhang, W. Ong, T. Lee, Exp. Brain Res. 126 (1999) 509-516.

[26] U. Seegers, H. Potschka, W. Loscher, Epilepsia 43 (2002) 675-684.

[27] M. Rizzi, S. Caccia, G. Guiso, C. Richichi, J.A. Gorter, E. Aronica, M. Aliprandi, R. Bagnati, R. Fanelli, M. D'Incalci, R. Samanin, A. Vezzani, J. Neurosc. 22 (2002) 5833-5839.

[28] P. Kwan, G. Still, E. Butler, T. Gant, B. Meldrum, M. Brodie, Epilepsy 43 (2002) 1318-1323.

[29] A. Lazarowski, A.J. Ramos, H. García-Rivello, E. Girardi, Cell Mol. Neurobiol .24 (2004) 77-85.

[30] E.A. van Vliet, R. van Schaik, P.M. Edelbroek, R.A. Voskuyl, S. Redeker, E. Aronica, W.J. Wadman, J.A. Gorter, JPET 322 (2007) 141-147. 
[31] J. Auzmendi, A. Merelli, E. Girardi, S. Orozco-Suarez, L Rocha, A. Lazarowski, Mol. Cell Epilepsy 1 (2014) 3:1-9.

[32] A.L. Rabinowicz, J.M. Salvat, R.C. Leiguarda, F. Demonty, F. Salvat, A. Cervio, F. Manes, A. Lazarowski. Clin. Neuropharmacol. 20 (1997) 438-441.

[33] A. Lazarowski, M. Massaro, A. Schteinschnaider, S. Intruvini, G. Sevlever, A. Rabinowicz, Ther. Drug Monit. 26 (2004) 44-46.

[34] C. Höcht, A. Lazarowski, N.N. Gonzalez, J. Auzmendi, J.A. Opezzo, G.F. Bramuglia, C.A. Taira, E. Girardi, Neurosci. Lett. 413 (2007) 168-72.

[35] J.R. Hughes, Neurol. Res. 30 (2008) 920-5.

[36] E.A. van Vliet, R. van Schaik, P.M. Edelbroek, S. Redeker, E. Aronica, W.J. Wadman, N. Marchi, A. Vezzani, J.A. Gorter, Epilepsia 47 (2006) 672-80.

[37] T. Uematsu, M. Yamaoka, R. Doto, H. Tanaka, T. Matsuura, K. Furusawa, Arch. Oral Biol. 48 (2003) 87-90.

[38] P. Fagiolino, M. Vázquez, C. Maldonado, M. Esperanza Ruiz, M.G. Volonté, S. Orozco-Suárez, A. Lazarowski, Curr. Pharm. Des. 19 (2013) 6767-6774.

[39] P. Iannetti, A. Spalice, P. Parisi, Epilepsia 46 (2005) 967-9.

[40] Ch. Eger, Epilepsia 44 (2004) Suppl. 5: 9-15.

[41] D.J. Roberts, K.B.Goralski, Expert Opin. Drug Metab. Toxicol. 4 (2008) 1245-64.

[42] K. Kunishio, M. Okada, Y. Matsumoto, S. Nagao, Y. Nishiyama, J. Med. Invest. 53 (2006) 285-91.

[43] K.M. Comerford, T.J. Wallace, J. Karhausen, N.A. Louis, M.C. Montalto, S.P. Colgan, Cancer Res. 62 (2002) 3387-94.

[44] A. Lazarowski, L. Caltana, A. Merelli, M. Rubio, A. Ramos, A. Brusco, J. Neurol. Sci. 258 (2007) $84-92$.

[45] E. Aronica, S.M. Sisodiya, J.A. Gorter, Adv. Drug Deliv. Rev. 64 (2012) 919-29.

[46] E. Aronica, J.A. Gorter, G.H. Jansen, C.W. van Veelen, P.C. van Rijen, S. Leenstra, M. Ramkema, G.L. Scheffer, R.J. Scheper, D. Troost, Neuroscience 118 (2003) 417-29.

[47] R.M. Wadkins, P.D. Roepe. Int. Rev. Cytol. 171 (1997) 121-65.

[48] P.D. Roepe, Curr. Pharm. Des. 6 (2000) 241-60.

[49] C. Vanoye, A. Castro, T. Pourcher, L. Reuss, G. Altenberg, Am. J. Physiol. 276 (1999) C370-8.

[50] M. Müller, Neuroscience 97 (2000) 33-45.

[51] C. Le Duigou, V. Bouilleret, R. Miles, J. Physiol. 586 (2008) (Pt 20): 4891-904.

[52] J.A. Auzmendi, S. Orozco-Suárez, I. Bañuelos-Cabrera, M.E. González-Trujano, E. C. González, L. Rocha, A. Lazarowski, Curr. Pharm. Design 19 (2013) 6732-6738.

[53] T. Mizutani, M. Masuda, E. Nakai, K. Furumiya, H. Togawa, Y. Nakamura, Y. Kawai, K. Nakahira, S. Shinkai, K. Takahashi, Curr. Drug Metab. 9 (2008) 167-74.

[54] M.A. Valverde, M. Diaz, F.V. Sepulveda, D.R. Gill, S.C. Hyde, C.F. Higgins, Nature 355 (1992) $830-3$.

[55] B.K. Siesjö, R. von Hanwehr, G. Nergelius, G. Nevander, M. Ingvar, J. Cereb. Blood Flow Metab. 5 (1985) 47-57.

[56] D.M. Durand, E.H. Park, A.L. Jensen, Philos. Trans. R. Soc. Lond. B Biol. Sci. 365 (2010):2347-62.

[57] D.A. Prince, B.W. Connors, Adv. Neurol. 44 (1986) 275-99.

[58] A.J. Ramos, A. Lazarowski, M. Villar, A. Brusco, Cell. Mol. Neurobiol.24 (2004) 101-7.

[59] L. Nashef, Epilepsia 38 (1997) 6-8.

[60] S. Kirby, R.M, Epilepsia 36 (1995) 25-28.

[61] L. Nashef, F. Walker, P. Allen, J.W. Sander, S. Shorvon, D. Fish, J. Neurol. Neurosurg. Psychiatry 60 (1996)297-300.

[62] S. Tigaran, H. Molgaard, R. McClelland, M. Dam, A.S. Jaffe, Neurology 60 (2003) 492-495. 
[63] S.U. Schuele, P. Widdess-Walsh, A. Bermeo, H. Lüders, Cleve. Clin. J. Med. 74 (2007) Suppl 1:S121127.

[64] A.J. Lazarowski, H.J. García Rivello, G.L. Vera Janavel, L.A. Cuniberti, P.M. Cabeza Meckert, G.G. Yannarelli, A. Mele, A.J. Crottogini, R.P. Laguens. J. Histochem. Cytochem. 53 (2005) 845-850.

[65] R.P. Laguens, A.J. Lazarowski, L.A. Cuniberti, G.L. Vera-Janavel, P.M. Cabeza Meckert, G.G. Yannarelli, H.F. del Valle, E.C. Lascano, J.A. Negroni, A.J. Crottogini, J. Histochem. Cytochem. 55 (2007) 191-197.

[66] J.Auzmendi, A. Merelli, E. Girardi, S. Orozco-Suarez, L. Rocha, A. Lazarowski, Mol. Cell. Epilepsy 1 (2014) e66. doi: 10.14800/mce.66.

[67] E. Brodtkorb, G. Nilsen, O. Smevik, P.A. Rinck, Acta Neurol. Scand. 86 (1992) 24-32.

[68] S.M. Sisodiya, J. Heffernan, M.V. Squier, Neuroreport 10 ((1999) 3437-41.

[69] A. Lazarowski, F. Lubieniecki, S. Camarero, V. Cuccia, A.L.Taratuto. Receptor Clin. Invest. 1 (2014) e53. doi: $10.14800 /$ rci.53

[70] J. Fassunke, M. Majores, C. Ullmann, Ch.E. Elger, J. Schramm, O.D. Wiestler, A.J. Becker, Lab. Invest. 84 (2004)1520-1525.

[71] C. Reali, F. Scintu, R. Pillai, S. Cabras, F. Argiolu, M.S. Ristaldi, M.A. Sanna, M. Badiali, V. Sogos. Exp. Neurol. 197(2006) 399-406.

[72] S. Fauser, A. Becker, A. Schulze-Bonhage, M. Hildebrandt, I. Tuxhorn, H.W. Pannek, R. Lahl, J. Schramm, I. Blumcke, Acta Neuropathol. 108 (2004) 272-8.

[73] M.S. van Breemen, E.B. Wilms, C.J. Vecht. Lancet Neurol. 6 (2007) 421-30.

[74] T. Lin, O. Islam, K. Heese, Cell Res. 16 (2006) 857-871.

[75] T. Schumacher, M. Krohn, J. Hofrichter, C. Lange, J. Stenzel, J. Steffen, T. Dunkelmann, K. Paarmann, C. Fröhlich, A. Uecker, A.S. Plath, A. Sommer, T. Brüning, H.J. Heinze, J. Pahnke. PLoS One 7 (2012) e35613

[76] L. Czornyj, A. Lazarowski. Front. Biosci. 19 (2014) 1425-1435.

(C2015 by the authors; licensee IAPC, Zagreb, Croatia. This article is an open-access article distributed under the terms and conditions of the Creative Commons Attribution license (http://creativecommons.org/licenses/by/3.0/) (cc)) EY 